\title{
Produção de rabanete sob o efeito residual da adubação verde no consórcio de beterraba e rúcula
}

\section{Radish production under the residual effect of green manure in the consortium beet and arugula}

\author{
Antônia Kênnia Oliveiral', Jailma Suerda Silva de Lima², Alany Moisa Almeida Bezerra³, Gardênia Silvana Oliveira \\ Rodrigues ${ }^{4}$, Maria Luiza Souza Medeiros ${ }^{5}$
}

\begin{abstract}
Resumo: Sistemas de cultivo com incorporação de adubos verdes podem preservar a capacidade produtiva do solo em longo prazo, oferecendo resíduos que proporcionarão melhorias nas condições físicas, química e biológica do solo tornando-o propício para a implantação de uma cultura sucedente. Diante disso, o trabalho teve como objetivo avaliar produção de rabanete sob o efeito residual da adubação verde no consórcio de beterraba e rúcula. O delineamento experimental usado foi em blocos casualizados com cinco repetições. Os tratamentos utilizados foram o efeito residual de quatro quantidades de florde-seda incorporadas ao solo $(10,25,40$ e 55 t ha-1 em base seca). As características avaliadas na cultura do rabanete foram: altura e diâmetro de plantas, número de folhas, produtividade total e comercial de raízes, massa seca da parte aérea e de raízes. $\mathrm{O}$ efeito residual da incorporação de flor-de-seda ao solo na quantidade de $55 \mathrm{t}$ ha-1 ${ }^{1}$ proporcionou a maior produtividade de raízes comerciais de rabanete, e assim podemos afirmar que a adubação verde com flor-de-seda apresenta-se como uma prática promissora para o produtor de hortaliças em cultivo sucessivo.
\end{abstract}

Palavras-chaves: Raphanus sativus. Beta vulgaris. Eruca sativa. Calotropis procera. Cultura sucedente.

Abstract: Cropping systems in with incorporation of green manures can preserve the productive capacity of the soil over time providing waste to the soil improvement in the conditions physical, chemical and biological, making it suitable for the implementation of a succeeding crop. Therefore the aim of this study was to evaluate the radish production under the residual effect of green manure in the consortium beet and arugula. The experimental design was a randomized complete block design with five replications. The treatments were the residual effect of four amounts of fleur-de-silk incorporated into the soil (10, 25, 40 and 55 t ha- $^{1}$ dry basis). The characteristics evaluated in the radish production were: plant height, diameter, total and commercial yield of roots, dry weight of shoots and roots. The residual effect of the fleur-de-silk incorporation into the soil in the amount of $55 \mathrm{t} \mathrm{ha}^{-1}$ provided the highest yield of commercial radish roots. The green manure with fleur-de-silk was presented as a promising practice for the producer of vegetables in succeeding crop.

Key words: Raphanus sativus. Beta vulgaris. Eruca sativa. Calotropis procera. Succeeding crop.

\footnotetext{
*Autor para correspondência

Recebido para publicação em 28/09/2015; aprovado em 20/12/2015

${ }^{1}$ Mestranda em fitotecnia, Univerisdade Federal Rural do Semi-Árido, Mossoró; Fone: (84)98861-1599, E-mail: kennia_agronomia@ @otmail.com.

${ }^{2}$ D.Sc. Pofessor Adjunto IV, Univerisdade Federal Rural do Semi-Árido, Mossoró; Fone: (84)98777-8569, E-mail: jailma@ufersa.edu.br.

${ }^{3}$ Mestranda em Sistemas Agroindustriais, Univerisdade Federal de Campina Grande, Campina Grande; E-mail: alanymoisa1@ hotmail.com

${ }^{4}$ D.Sc. Pofessora Adjunto I, Faculdade Mater Christi, Mossoró; E-mail: gardeniavg@ hotmail.com.

${ }^{5}$ M.Sc. em Ciências Florestais, Univerisdade Federal do Rio Grande do Norte, Natal; E-mail: luizamedeiros30@hotmail.com.
} 


\section{INTRODUÇÃO}

Em virtude de uma maior conscientização da população em consumir alimentos saudáveis, sem contaminantes tóxicos, associada à busca pela sustentabilidade na agricultura, com o uso racional dos recursos naturais e insumos para a produção de alimentos o consumidor está mais exigente, e com o intuito de atendê-lo, o produtor busca alternativas para satisfazê-las. Nesse contexto encontra-se, a adubação orgânica que é uma das práticas de cultivo existentes, fornecedora de matéria orgânica e nutrientes para as plantas, possibilitando a redução da quantidade de adubos químicos aplicados (BUZINARO et al., 2009).

Esta além de proporcionar maior conservação ambiental e produzir alimentos mais saudáveis permitirá um maior emprego de mão-de-obra familiar, o que contribui para a fixação do homem no campo com retorno econômico mais satisfatório (KHATOUNIAN, 2001; SOUZA, RESENDE, 2006). Essa atividade diminui a necessidade de uso de adubos minerais e possibilitam o aumento nutricional do vegetal (SOUZA et al., 2005).

Dessa forma, a utilização de insumos alternativos, como os adubos verdes, pode contribuir para reposição de nutrientes ao solo, a exemplo do $\mathrm{N}$, como também auxiliar na ciclagem dos nutrientes ao trazer para a superfície do solo nutrientes que estão em maior profundidade. Além de, favorecem a manutenção da matéria orgânica do solo e o "sequestro" de carbono da atmosfera, recuperando solos degradados e controlando plantas daninhas.

Nas áreas de cultivo agrícola, as espécies vegetais espontâneas, tratadas como "plantas daninhas", acarretam nas espécies cultivadas, prejuízos, por competirem por nutrientes, água e luz. No entanto, as espécies espontâneas podem promover os mesmos efeitos de cobertura do solo, produção de biomassa e ciclagem de nutrientes que as espécies introduzidas ou cultivadas para adubação verde.

Em vários trabalhos são apresentados efeito positivo de adubos verdes com espécies espontâneas da caatinga, como a incorporação de jitirana (Merremia aegyptia L.), de mata pasto (Senna uniflora L.) e de flor-de-seda (Calotropis procera L.) (BARROS JUNIOR et al., 2009).

Entretanto um dos aspectos pouco explorados e que contribui para reduzir o custo da adubação é o efeito residual dos adubos verdes, ou seja, as quantidades de nutrientes existentes no solo após cada ciclo cultural e como os mesmos se comportam no solo. De acordo com Filgueira (2003), numa sucessão de culturas oleráceas, é primordial estimar o efeito residual das adubações anteriormente aplicadas, já que é impossível fornecer os nutrientes na medida exata para atender, tão somente, à demanda da cultura visada.

$\mathrm{Na}$ literatura encontram-se resultados promissores através do cultivo de hortaliças sucedentes a adubação verde. Perin et al. (2004) pesquisando o efeito residual da adubação verde no rendimento de brócolos cultivados na sucessão ao milho, registraram aumentos no teor de nitrogênio acumulado nas folhas e nas inflorescências dos brócolos. Linhares et al. (2011), no cultivo do coentro em sucessão ao cultivo de alface adubado com quantidades crescentes de flor-de-seda, otimizaram a produtividade e a massa seca da parte aérea do coentro com as quantidades residuais de 8,02 e 7,60 tha- ${ }^{1}$ de flor-de-seda incorporadas ao solo. Linhares et al. (2010) avaliando o efeito residual de quantidades crescentes de jitirana na produção de rabanete observaram um aumento na produtividade comercial de raízes e na massa seca.

Essa prática traz benefícios para o pequeno produtor, uma vez que em decorrência da gradativa decomposição dessas plantas favorecerá uma maior produção de fitomassa e ciclagem de nutrientes, com alguns nutrientes estando disponíveis no solo (LINHARES et al., 2011), e não sendo necessário a realização de uma nova adubação, reduzindo as despesas na produção e possibilitando resultados satisfatórios, principalmente em culturas de ciclo curto. Diante disso, o trabalho teve como objetivo avaliar produção de rabanete sob o efeito residual da adubação verde no consórcio de beterraba e rúcula.

\section{MATERIAL E MÉTODOS}

O experimento foi conduzido na Fazenda Experimental Rafael Fernandes da Universidade Federal Rural do Semiárido- UFERSA, no distrito de Alagoinha, Zona rural do município de Mossoró-RN. Situada a $5^{\circ} 03^{\prime}$ de latitude sul, $37^{\circ} 24^{\prime}$ de longitude oeste e altitude de $18 \mathrm{~m}$, segundo Thornthwaite, o clima da região é semiárido e, de acordo com Koppen, é BsWh, seco e muito quente, com duas estações climáticas: uma seca, que vai geralmente de junho a janeiro e uma chuvosa, de fevereiro a maio (CARMO FILHO, 1991).

O solo desta área é classificado como Argissolo Vermelho Amarelo Eutrófico (EMPRABA, 2006). Antes da instalação do experimento, foram coletadas amostras de solo, a uma camada de $0-20 \mathrm{~cm}$. Estas foram analisadas no Laboratório de Química e Fertilidade do Solo e Nutrição de Plantas, da UFERSA, fornecendo os seguintes resultados: $\mathrm{N}=$ $0,59 \mathrm{~g} \mathrm{kg-}^{-1} ; \mathrm{pH}=6,12 ; \mathrm{P}=3,75 \mathrm{mg} \mathrm{dm}{ }^{-3} ; \mathrm{K}=70,82 \mathrm{mg} \mathrm{dm}-$ 3; $\mathrm{Ca}=1,98 \mathrm{cmol}_{\mathrm{c}} \mathrm{dm}^{-3} ; \mathrm{Mg}=0,68 \mathrm{cmol}_{\mathrm{c}} \mathrm{dm}^{-3} ; \mathrm{Na}=7,8 \mathrm{mg}$ dm- ${ }^{3}$; CE=0,18 dS m-1; M.O.=7,82 g kg-1; $\mathrm{SB}=2,88$ cmol $_{\mathrm{c}}$ $\mathrm{dm}^{-3} ; \mathrm{CTC}=3,48 \mathrm{cmol}_{\mathrm{c}} \mathrm{dm}^{-3} ; \mathrm{PST}=1 \% ; \mathrm{t}=2,88 \mathrm{cmol}_{\mathrm{c}} \mathrm{dm}^{-3} \mathrm{e}$ $\mathrm{V}=83 \%$.

O delineamento experimental utilizado foi em blocos casualizados com quatro tratamentos e cinco repetições. Os tratamentos consistiram do efeito residual de quatro quantidades de flor-de-seda incorporadas ao solo $(10,25,40 \mathrm{e}$ 55 t ha- $^{1}$ em base seca).

As parcelas experimentais no sistema consorciado foram adubadas com as respectivas quantidades de flor-de-seda (10, 25, 40 e $55 \mathrm{t} \mathrm{ha}^{-1}$ em base seca). A incorporação foi realizada em duas etapas dividindo-se as quantidades em duas partes, $50 \%$ incorporadas na camada de $0-20 \mathrm{~cm}$ do solo, 20 dias antes do transplantio das mudas e o restante $50 \%$ incorporadas em cobertura 45 dias após o transplantio. A área total da parcela foi de $3,60 \mathrm{~m}^{2}$, formada por fileiras quádruplas de beterraba alternadas com fileiras quádruplas de rúcula, ladeadas pelas mesmas fileiras-bordadura de cada cultura, com uma área útil de 2,0 m².

A flor-de-seda foi coletada da vegetação nativa, em propriedades periféricas à cidade de Mossoró. As plantas foram cortadas manualmente com o auxílio de facão, extraindo-se apenas a parte verde da planta. Em seguida, o material foi triturado em forrageira mecânica (deixando-se pedaços de $2-3 \mathrm{~cm}$ ) e submetido ao processo de secagem em pleno sol, até se obter em torno de $10 \%$ de umidade.

Após a colheita da beterraba e da rúcula foi realizado o plantio do rabanete, no espaçamento $0,20 \mathrm{~m} \times 0,05 \mathrm{~m}$, onde as sementes foram colocadas, aproximadamente 3 a cinco 
sementes. Aos sete dias após a emergência foi realizado o desbaste deixando-se uma planta por cova. A cultivar de rabanete utilizada foi a Crimson Gigante.

O sistema de irrigação utilizado foi micro-aspersão, com turno de rega diário parcelado em duas aplicações (manhã e tarde), fornecendo-se uma lâmina de água de aproximadamente $8 \mathrm{~mm} \mathrm{dia}{ }^{-1}$. Durante a condução do experimento foram realizadas capinas manuais.

A colheita do rabanete foi realizada aos 30 dias após o plantio, colhendo-se apenas a área útil da parcela. As características avaliadas no rabanete foram: altura de plantas, determinada numa amostra de cinco plantas selecionadas da parcela útil, através de uma régua graduada, a partir do nível do solo até a extremidade das folhas mais altas, expressas em centímetro.

Diâmetro de plantas, obtido na mesma amostra anterior, medindo-se os diâmetros entre as margens opostas do disco foliar, em seguida, obtendo-se a média e expressando os resultados em $\mathrm{cm}$.

Número de folhas por planta, obtido pela contagem das folhas basais até a última folha aberta, na mesma amostra anterior.

Produtividade total, determinada pela massa fresca das raízes das plantas da área útil expressa em $\mathrm{t} \mathrm{ha}^{-1}$.

Produtividade comercial de raízes, determinada a partir da massa fresca das raízes das plantas da área útil livres de rachaduras, não isoporizadas (CARDOSO; HIRAKI, 2001) e expressa em tha ${ }^{-1}$.

Massa seca da parte aérea e de raiz, obtida na mesma amostra de cinco plantas, colocando-a em estufa com circulação de ar forçada em temperatura de $65^{\circ} \mathrm{C}$ até atingir peso constante, e expresso em t ha-1.

Os dados foram submetidos a análise de variância, e para os fatores de natureza quantitativa (quantidades de flor- de-seda), realizou-se a análise de regressão utilizando-se o software Table Curve (JANDEL SCIENTIFIC, 1991).

\section{RESULTADOS E DISCUSSÃO}

Para as características altura de plantas e diâmetro de raízes observou-se um aumento suave dessas características à medida que aumentou-se as quantidades de flor-de-seda incorporadas ao solo, obtendo-se a maior altura de $12,23 \mathrm{~cm}$ na quantidade residual de $46 \mathrm{t}^{\text {ha- }}{ }^{1}$ de flor-de-seda incorporada ao solo (Figura $1 \mathrm{~A}$ ). O maior diâmetro, $2,98 \mathrm{~cm}$, foi observado na quantidade de $55 \mathrm{t} \mathrm{ha-}^{-1}$ (Figura $1 \mathrm{C}$ ). Por outro lado, não foi possível ajustar nenhuma função resposta para o número de folhas por planta em função das quantidades de flor-de-seda incorporadas ao solo, obtendo um valor médio de 5,45 folhas (Figura $1 \mathrm{~B}$ ).

Os resultados obtidos neste trabalho concordam com os verificados por Linhares et al. (2011a), onde o valor máximo de 13,68 cm para altura de plantas de rabanete foi obtido na maior quantidade 12,0 t ha-1 ${ }^{1}$ do mesmo adubo. Em relação ao diâmetro de raizes, valores superiores a este trabalho foi obtido por Henriques et al. (2011) que obteve diâmetro de 4,49 no rabanete para a quantidade residual de $15,6 \mathrm{t} \mathrm{ha}^{-1}$ de flor-de-seda. Vitti et al. (2007) estudando adubação orgânica no rabanete, observaram no diâmetro horizontal $3,7 \mathrm{~cm}$ planta $^{-1}$ na presença de $20 \mathrm{~g}$ de esterco bovino. Esses diâmetros estão dentro do padrão de comercialização para esta hortaliça no mercado consumidor local (LINHARES et al., 2010). Quanto ao número de folhas valores superiores foram encontrados por Linhares et al. (2010), constataram uma média de 8 folhas planta $^{-1}$ quando avaliaram o efeito residual de quantidades de jitirana incorporada ao solo na produtividade do rabanete.

Figura 1. Altura de plantas (A), número de folhas (B) e diâmetro de raízes (C) de rabanete em função do efeito residual das quantidades de flor-de-seda incorporadas ao solo. Mossoró-RN, 2015. Plant height (A), number of leaves (B) and root diameter $(\mathrm{C})$ in function quantities of silk -flower incorporated into the soil. Mossoró-RN, 2015.
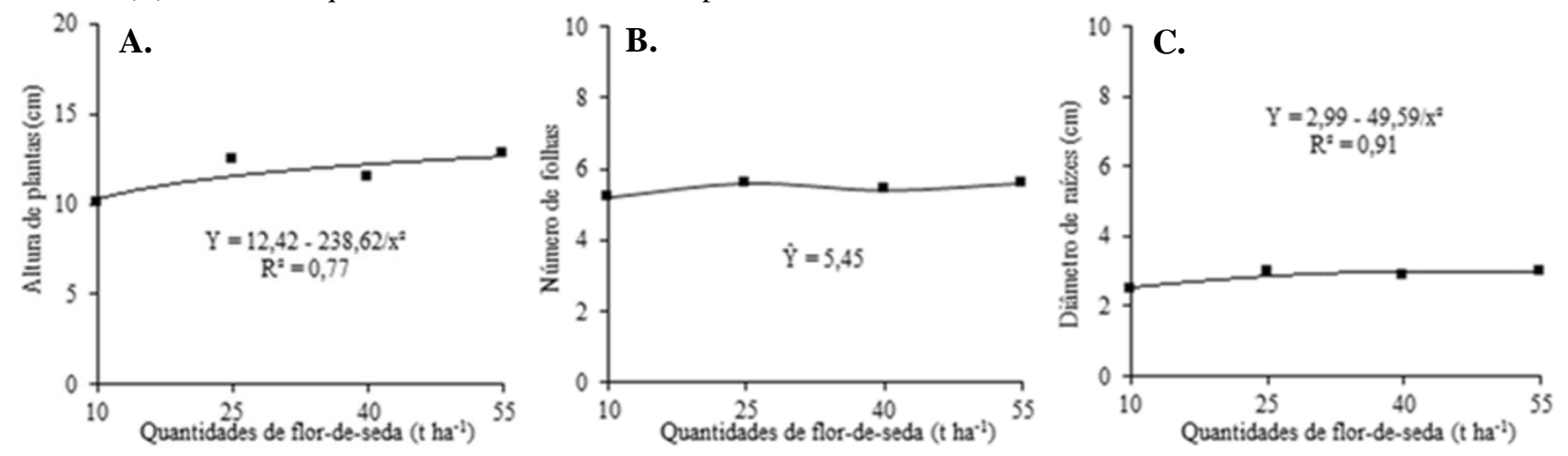

A produtividade total e comercial de raízes de rabanete aumentou com as quantidades residuais crescentes de flor-deseda com o valor máximo de 7,0 e 6,0 t ha- ${ }^{1}$ na quantidade de 55 t ha- $^{1}$ incorporada ao solo, respectivamente (Figura 2A; Figura 2B). Esses valores foram superiores ao encontrado por Moreira et al. (2013) que obteve 4,69 $\mathrm{t} \mathrm{ha}^{-1}$ na quantidade $12,42 \mathrm{t} \mathrm{ha}^{-1}$ de jitirana. Esse aumento deve-se provavelmente, à maior disponibilidade de nutrientes liberados pela flor-deseda, como também à sincronia na qual esses elementos são liberados e absorvidos pela planta. Essas observações comprovam a influência do efeito residual da flor-de-seda no solo, proporcionando essa exteriorização em ganho de massa pela planta.

Segundo Fontanétti et al. (2006), a absorção de nutrientes advindos da mineralização de adubos verdes pelas hortaliças depende, em grande parte, dessa sincronia entre a decomposição e mineralização dos resíduos vegetais e da época de maior exigência da cultura, (C:P) (XU; HIDRATA, 2005). 
Figura 2. Produtividade total (A) e produtividade comercial (B) de raízes de rabanete em função dos resíduos das quantidades de flor-de-seda incorporadas ao solo. Mossoró-RN, 2015. Total root yield (A) and commercial yield (B) in function quantities of silk-flower incorporated into the soil. Mossoró-RN, 2015.

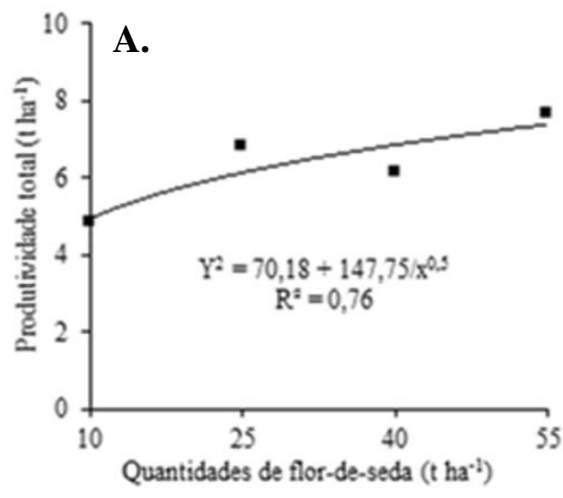

Para a massa seca da parte aérea e das raízes nenhuma função resposta foi encontrada obtendo um valor médio de $0,3058 \mathrm{t} \mathrm{ha}^{-1}$ e $0,3645 \mathrm{t} \mathrm{ha}^{-1}$, respectivamente (Figura 3B). Esses resultados devem-se aos principais benefícios da adubação verde no solo como a adição de matéria orgânica, melhoria da estrutura do solo, a capacidade de retenção de umidade, consistência e densidade e a maior disponibilidade de nutrientes ao solo, onde o adubo verde coloca-os na zona

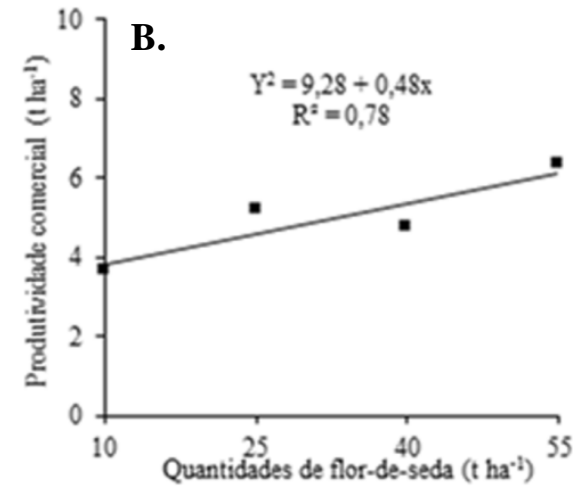

de enraizamento da superfície e torna-os disponíveis para a cultura seguinte. Além disso, servindo de proteção contra a erosão (perda do solo) e diminuição da lixiviação (lavagem) de nutrientes, reduzindo as oscilações de temperaturas das camadas superficiais do solo e diminuindo a evaporação, aumentando a disponibilidade de água para as culturas e reduzindo a população de plantas espontâneas no cultivo convencional (ALCANTARA, 2009).

Figura 3. Massa seca da parte aérea (A) e massa seca de raízes (B) de rabanete em função dos resíduos das quantidades de flor-de-seda incorporadas ao solo. Mossoró-RN, 2015 Shoot, dry mass (A) and root dry matter (B) in function quantities of silk -flower incorporated into the soil. Mossoró-RN, 2015.

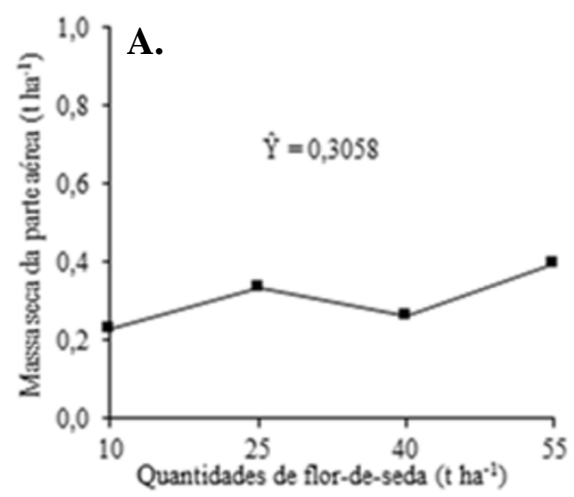

Dessa forma a incorporação ao solo de plantas com elevada produção de biomassa, rica em nutrientes, pode elevar os teores de nutrientes, proporcionando a conservação ou aumento da matéria orgânica do solo, e este de acordo com o seu grau de decomposição, pode ter efeito imediato ou residual, por isso sua importância sob o ponto de vista econômico e da conservação das propriedades físicas, químicas e biológicas do solo.

\section{CONCLUSÃO}

1. O efeito residual da incorporação de flor-de-seda ao solo na quantidade de $55 \mathrm{t} \mathrm{ha}^{-1}$ proporcionou a maior produtividade de raízes comerciais de rabanete, com isso podemos afirmar que a adubação verde com flor-de-seda apresenta-se como uma prática promissora para o produtor de hortaliças em cultivo sucessivo.

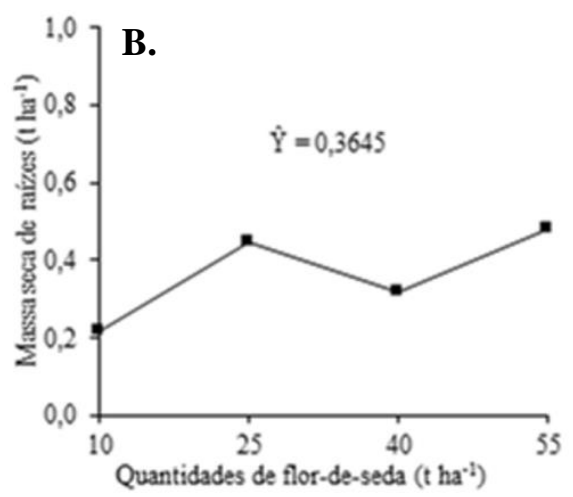

\section{REFERÊNCIAS BIBLIOGRÁFICAS}

ALCANTARA, F. A. de. As vantagens da adubação verde. Brasília: Embrapa Hortaliças, 2009. Disponivel em: <ecampo.com.br/Conteudo/Artigos/visArtigos>. Acesso em: 1 nov 2011.

ALMEIDA, A. M. B.; LINHARES, P. C. F.; FILHO, J. L.; NEVES, A. P. M.; MORAIS, S. L. S. Efeito residual da jitirana, flor-de-seda e mata-pasto no cultivo da rúcula em sucessão a beterraba. Revista Verde de Agroecologia e Desenvolvimento Sustentável, Pombal, v.10, n.2, p.42$48,2015$.

BARROS JUNIOR, A. P.; BEZERRA NETO, F.; SILVEIRA, L. M.; LINHARES, P. C. F.; MOREIRA, J. N.; SILVA, M. L.; PACHECO, I. W. L.; OLIVEIRA, M. K.T.; FERNANDES, Y. T. D. Avaliação produtiva de coentro em diferentes tipos e quantidades de adubos 
verdes aplicados ao solo. Horticultura Brasileira, Brasília, v. 27, n. 32, p.288-293, 2009.

BUZINARO, T. N.; BARBOSA, J. C.; NAHAS, E. Atividade microbiana do solo em pomar de laranja em resposta ao cultivo de adubos verdes. Revista Brasileira de Fruticultura, Jaboticabal, v. 31, n. 2, p. 408-415, 2009.

CARDOSO, A. I. I.; HIRAKI, H. Avaliação de doses e épocas de aplicação de nitrato de cálcio em cobertura na cultura do rabanete. Horticultura Brasileira, Brasília, v. 19, n. 3, p.328-331, 2001.

CARMO FILHO, F.; ESPÍNOLA SOBRINHO, J.; MAIA NETO, J. M. Dados climatológicos de Mossoró: um município semiárido nordestino. Mossoró: ESAM, 1991, 121p. (Coleção Mossoroense, série C, 30).

EMBRAPA. Centro Nacional de Pesquisa de Solos. Sistema brasileiro de classificação de solos. Brasília: Embrapa Produção de Informação. Rio de Janeiro: Embrapa Solos, 2006. 306 p.

FILGUEIRA, F. A. R. Novo Manual de Olericultura: Agrotecnologia moderna na produção e comercialização de hortaliças. Viçosa: UFV. 2008. 402 p.

FONTANÉTTI, A.; CARVALHO, G. J.; GOMES, L. A. A.; ALMEIDA, K.; MORAES, S. R. G.; TEIXEIRA, C. M. Adubação verde na produção orgânica de alface americana e repolho. Horticultura Brasileira, Brasília, v. 24, n. 2, p.146-150, 2006.

HENRIQUES, G. P. S. A; LINHARES, P. C. F.; SOLANO, B. O.; PAULINO, R. C.; PEREIRA, M. F. S. Efeito residual da flor-de-seda (Calotropisprocera(Aiton) W. T. Aiton) no desempenho agronômico do rabanete. Cadernos de Agroecologia, Fortaleza, v.6, n.2, p. 1-5, 2011.

JANDEL SCIENTIFIC. Table curve: curve fitting software. Corte Madera, CA: Jandel Scientific, 1991. 280p.

KHATOUNIAN, C. A. A reconstrução ecológica da agricultura. Botucatu: Agroecologia, 2001. 348p.

LINHARES, P. C. F.; OLIVEIRA, R. M.; PEREIRA, M. F. S; SILVA, M. L. O. Adubação verde em diferentes proporções de jitirana com mata-pasto incorporado ao solo no coentro. Revista Verde de Agroecologia, Mossoró- RN, v. 5, n. 1, p. 91-95, 2010.
LINHARES, P. C. F.; PEREIRA, M. F. S.; OLIVEIRA, B. S.; HENRIQUES, G. P. S. A. Produtividade de rabanete em sistema orgânico de producão. Revista Verde de Agroecologia e Desenvolvimento Sustentável, Pombal, v.5, n.5, p.94-101, 2010.

LINHARES, P. C. F.; PEREIRA, M. F. S.; PAZ, A. E. S.; PAIVA, A.C.C.; BEZERRA, A.K.H.; FERNANDES, P. L. O. Efeito residual de espécies espontâneas da caatinga no desempenho agronômico do coentro. Cadernos de Agroecologia, Cruz das Almas, v. 6, n. 2, p. $1-5,2011$.

LINHARES, P. C. F; SILVA, M.L; PEREIRA, M. F. S.; BEZERRA, A. K. H; PAIVA, A. C. C. Quantidades e tempos de decomposição da flor-de-seda no desempenho agronômico do rabanete. Revista Verde de Agroecologia e Desenvolvimento Sustentável, Mossoró, v.6, n.1, p.168-173, 2011.

MOREIRA, J. N.; BEZERRA NETO, F.; ANDRADE FILHO, F. C.; SILVA, A. R.; SOARES, A. M. Viabilidade produtiva de rabanete sod efeito residual de consórcios de coentro e rúcula. Cadernos de Agroecologia, Porto Alegre, v. 8, n. 2, 2013.

PERIN, A.; SANTOS, R. H. S.; URQUIAGA, S.; GUERRA, J. G. M.; CECON, P. R. Efeito residual da adubação verde no rendimento de brócolo (BrassicaoleraceaeL. var.italica) cultivado em rotação de culturas com milho. Ciência Rural, Santa Maria, v. 34, n. 6, p.1739-1745, 2004.

SOUZA, P.A.; NEGREIROS, M. Z.; MENEZES, J. B.; BEZERRA NETO, F.; SOUZA, G. L. F. M.; CARNEIRO, C. R.; QUEIROGA, R. C. F. Características químicas de folhas de alface cultivada sob efeito residual da adubação com composto orgânico. Horticultura Brasileira, Brasília, v. 23, n.3, p. 699-702, 2005.

SOUZA, J. L.; RESENDE, P. Manual de horticultura orgânica. 2.ed. Viçosa: Aprenda Fácil, 2006. 843p.

VITTI, M. R.; VIDAL, M. B.; MORSELLI, T. B. G. A.; FARIA, J. L. C. Resposta do rabanete a adubação orgânica em ambiente protegido. Revista Brasileira de Agroecologia, Pelotas, v. 2, n. 1, p. 1158-1161, 2007.

XU, X.; HIDRATA, E. Decomposition patterns of leaf litter of seven common canopy species in a subtropical Forest: N and P dynamics. Plant and Soil, Dordrecht, v. 273, n. 1-2, p. 279-289, 2005. 